\title{
On Student Safety and Philosophical Dialogue
}

\author{
Douglas W. Yacek \\ Dortmund University
}

Allison Stevens and I share a common concern. Violence in public schools has become a tragic mainstay of the American educational system. The gruesome outbursts of carnage that school shootings represent are now a recurring phenomenon of American life. When these events take place, one is overcome with profound sadness and despair. Stevens' impassioned plea to the guardians of our next generation-to parents, teachers, politicians, and other adults-is a putting-one's-foot-down before this disturbing trend gets any worse, and I hope very much that it has its intended effect.

I am not very optimistic that it will, however. In my own engagement with the American gun debate-and, in particular, with the debate about arming public school teachers-I have observed that impassioned pleas are the norm. 'Both sides of the debate (insofar as there are only "two sides") regularly draw on the pathos of school shootings, with one side conjuring the image of helpless and vulnerable children left without the protection of the proposed school safety measure, while the other side alludes to the prison-like atmosphere that such measures create. ${ }^{2}$ Against this backdrop, each side expresses righteous indignation towards those who stand in their way, levying strident accusations of the other's cruel readiness to expose children to harm. In doing so, rhetoric tends to get in the way of reason, as the debate is overrun by dramatic oversimplifications and profound misunderstandings of the ethical complexities of ensuring student safety.

Stevens puts forth an effort to bring some needed reasoning and ethical reflection to the school safety debate, but I do not think her commitment to reasoned and nuanced discussion goes far enough. Stevens' 
analysis frequently gets caught up in imprecise generalizations about her topic, especially with respect to whom she thinks is responsible for school violence. According to Stevens, the people responsible for the problem of school violence is, simply, adults: "the critique is leveraged against the American adults who have had greater opportunity to influence national culture (in terms of years) and are able to vote." ${ }^{3}$ Of course, Stevens is right that adults share responsibility for the phenomenon of school violence. However, Stevens' accusation that adults "have allowed their inert political ideology to be a stand-in for actions that would have helped prevent school firearm violence" is, I think, an example of rhetoric getting in the way of reason. First, there are many adults-Stevens, too?-who care deeply about the problem of school violence and who have attempted to understand its causes and implications for modern schooling. Their concern with this topic may not have brought about the change Stevens and we all hope to see, but to call their ideology "inert" is to misunderstand what it means to live in a complex and pluralistic democratic society. The problem is that there is simply no direct line in democratic societies from one's activist aspirations to public policy. Pluralism means in practice that one's own visions of what constitutes a good society or a good public school inevitably run up against contrasting visions. In the US, there is a large swath of the population for whom the possession of guns is an important cultural practice. The adult who wants to change something in public policy regarding gun ownership and carriage will continually run up against this fact, not to mention many other socio-cultural factors that will counteract what he or she considers progress. The prominence that school shootings receive in the mass media is a clear example of such a factor, as the visibility that such treatment provides is often a perverse motivator for school shooters. ${ }^{4}$ In such circumstances, it is quite odd to blame those concerned about school safety for the factors that foil their efforts. Let us not forget that the parents of the victims of school shootings are in this group.

Stevens might insist that such "socio-cultural factors" are precisely 
the things that adults should have changed before things got this bad. The problem, however, is that it is hard to know what to do about them, especially in advance. Consider the media example just given. What should "adults" do exactly about the prominence of school shootings in the media? Should they forbid media outlets from covering shootings? Should we hold "adults" accountable for not having foreseen the mass media's potential influence on student safety? This is also an odd sort of expectation. After all, such factors, including the phenomenon of school violence itself, are often part of very large and powerful historical processes, over which individuals or "adults" have little control, at least in any straightforward sense. Placing the blame simply on "adults" thus distracts from the deeper culprits of social malaise.

This brings me to the second point that Stevens'analysis overlooks. What Stevens' plea seems to have missed is that we are actually living in a time of great enthusiasm towards implementing measures to improve school safety. The problem is not inertia in school safety policy, but rather the explosive accumulation of safety measures - from surveillance cameras and metal detectors to regular lockdown drills and shooter training programs for teachers - that have steadily transformed the character of many American public schools. The productive question in this context, which Stevens does not pose, is which measures are the right ones for preserving the integrity of students' education in the face of school violence. What happens to students' educational experience when surveillance cameras are introduced into schools? How might armed teachers influence the quality of democratic learning that occurs in schools? Are windowless classrooms the right way to shore up defenses against a school shooter? How can educators provide the requisite psychological care to "at risk" students without labeling them in a damaging way? It seems to me that critiques like Stevens' that remain vague on important questions like these-questions that require subtle and fine-grained ethical analysis-are actually examples of the kind of idleness that Stevens laments.

In making these two criticisms, I do not mean to say that Stevens' 
project is not worthwhile. In fact, it is so worthwhile that I want to see it at its strongest. As philosophers of education, I think we have a very important contribution to make in seemingly vexed debates like the one concerning student safety. Philosophical analysis and dialogue allow us to resist the temptations of rhetorical grandstanding, which worsens the polarized climate of discussion, and adopt a form of communication that is welcoming to a diversity of views and values. In weighing the perspectives of the concerned parties in a sensitive and nuanced way, we not only show the kind of respect and responsiveness that each party deserves. We also stand to formulate much more robust proposals for how to make our schools better places, proposals that just might find common ground.

1 Douglas Yacek, "America's Armed Teachers: An Ethical Analysis,"Teachers College Record 120, no. 8 (2018): 1-36.

2 For a compelling defense of the latter position, see Drew Chambers, "How School Security Measures Harm Schools and Their Students," Educational Theory, forthcoming.

3 Allison Stevens, "Holding Americans Accountable and Centering Students," Philosophy of Education 77, no. 3 (2021).

4 Bryan Warnick, Sang Hyun Kim, and Shannon Robinson, "Gun Violence and the Meaning of American Schools," Educational Theory 65, no. 4 (2015): 371-386. 